\title{
High degree of duodenal inflammation in Nigerians with functional dyspepsia
}

This article was published in the following Dove Press journal:

Clinical and Experimental Gastroenterology

31 December 2013

Number of times this article has been viewed

Sylvester Chuks

Nwokediuko'

Uchenna N ljoma'

Olive Obienu'

Gideon E Anigbo'

Okechukwu Okafor ${ }^{2}$

'Department of Medicine, ${ }^{2}$ Department of Morbid Anatomy, University of Nigeria Teaching Hospital, Ituku/Ozalla Enugu, Nigeria

Correspondence: Sylvester Chuks Nwokediuko

Gastroenterology Unit, Department of Medicine, University of Nigeria Teaching Hospital Ituku/Ozalla, PMB 01129 Enugu, Nigeria Tel +234803 32I 8I8I

Emailscnwokediuko@yahoo.com
Background: Functional dyspepsia (FD) is a heterogeneous disorder associated with diverse pathophysiological mechanisms, including immune activation and low-grade mucosal inflammation. Genetic factors, physiological functions, and environmental factors may determine the relative importance of various pathophysiological mechanisms. This study was designed to determine the histological alterations in the duodenal mucosa of Nigerian patients with FD.

Methods: Consecutive patients with dyspepsia seen over a 27-month period in two gastrointestinal endoscopy facilities in Enugu, South-East Nigeria were further evaluated with upper gastrointestinal endoscopy and duodenal mucosal biopsies if no lesion was found in the upper gastrointestinal tract. Patients with heartburn and/or regurgitation who did not have any dyspeptic symptoms and did not have any lesion in the upper gastrointestinal tract on endoscopy were presumed to have non-erosive reflux disease (NERD) and they served as controls. The control subjects also had duodenal biopsies. The histopathological findings in the cases and controls were compared.

Results: There were 68 patients with FD and 52 patients with NERD. The total inflammatory score was 242 in FD and 66 in NERD (Mann-Whitney $U=1168, P=0.0011$ ). Similarly, the scores for chronic inflammation, gastric metaplasia, neutrophilic activity, eosinophilic infiltration, and Helicobacter pylori were significantly higher in FD than NERD.

Conclusion: Functional dyspepsia is associated with a high degree of inflammation in the duodenal mucosa. This may reflect the high prevalence of gastrointestinal infections in a tropical environment such as Nigeria. These findings may have therapeutic potential that further studies might elucidate.

Keywords: functional dyspepsia, duodenitis, Nigerians

\section{Introduction}

Functional dyspepsia (FD) is defined as the presence of symptoms that originate in the gastroduodenal region in the absence of any organic, systemic, or metabolic disease that readily explains the complaints. According to the Rome III criteria, the symptoms include bothersome postprandial fullness, easy satiation, epigastric pain, and epigastric burning. ${ }^{1}$

Worldwide, the majority of patients with dyspepsia have FD. ${ }^{2,3}$ The global prevalence of FD ranges from $11.7 \%$ in Asia, ${ }^{4} 20.6 \%$ in Europe, ${ }^{5}$ to $29 \%$ in the US. Population-based studies are scarce in Africa; however, in a population of African patients with dyspepsia, FD accounted for $66.6 \%{ }^{7}$

Functional dyspepsia is a heterogeneous disorder of unclear pathogenetic mechanism. Some of the mechanisms that have been proposed include delayed gastric 
emptying, impaired proximal gastric accommodation to a meal, gastric hypersensitivity to distension, abnormal duodenojejunal motility, low-grade inflammation, and psychological disturbance. ${ }^{8-12}$

Studies originating from Western Europe and North America have reported varying histological alterations in the duodenal mucosa of patients with FD. ${ }^{8,9,12}$ Environmental factors such as food, lifestyle, and prevalence of Helicobacter pylori infection are widely different in African countries compared to the West. Similarly, physiological functions and genetic factors of Africans may also be different from those of Westerners. Gastrointestinal infections are rife in Africa, ${ }^{13}$ a situation promoted by poor sanitation, rapid urbanization, and lack of potable water. ${ }^{14-18}$ This study aimed at determining the histological changes in the duodenal mucosa of Nigerian patients with FD.

\section{Patients and methods}

This was a prospective study of adult patients with FD at the gastroenterology unit of University of Nigeria Teaching Hospital Ituku/Ozalla, and Uzoma Specialist Hospital Trans Ekulu, both in Enugu, Nigeria from January 2011 to March 2013. Patients who underwent routine upper gastrointestinal endoscopy for postprandial fullness, early satiation, epigastric burning, and/or epigastric pain, and in whom no lesion was found in the upper gastrointestinal tract were presumed to have FD and they formed the study population. Patients who had heartburn and/or regurgitation and patients who had alarm symptom(s) were excluded. Also excluded were patients who had parasites in their stool or peripheral blood eosinophilia. Two mucosal biopsies were obtained from the duodenal cap and two from the second part of the duodenum. The specimens were properly labeled, fixed in 10\% buffered formalin, processed with paraffin embedding, and sectioned. Staining was done with hematoxylin and eosin (H\&E). Using the schema proposed by Serra and Jani, ${ }^{19}$ the following parameters were scored:

1. Chronic inflammatory cells: this ranged from 0 to 3 , representing normal, mild, moderate and severe, respectively.

2. Villus-Crypt ratio: this ranged from 0 to 2 , representing normal, partial villous atrophy, and total villous atrophy, respectively.

3. Brunner's gland hyperplasia and prolapse into lamina propria: this was scored 0 if absent, and 1 if present.

4. Gastric metaplasia: This was scored 0 for absent, 1 for complete, 2 for intermediate, and 3 for incomplete metaplasia. $^{20}$
5. Neutrophilic activity: this ranged from 0 to 2 , representing absent, present in pits/lamina propria, and present in surface epithelium, respectively.

6. Eosinophilic infiltration was scored from 0 to 2 , representing absent, present in pits/lamina propria, and present in surface epithelium, respectively.

7. Helicobacter pylori infection was scored 0 if absent and 1 if present.

Surface erosions and presence of other microorganisms were also noted. The total inflammatory score was computed for each patient.

The control arm of the study consisted of age and sexmatched patients with non-erosive reflux disease (NERD). These were patients who presented with heartburn and/or regurgitation, without any dyspeptic symptoms. They also had no stool parasites, no peripheral blood eosinophilia, and normal upper gastrointestinal tract on endoscopy. Duodenal biopsies were obtained from the control group and the biopsy specimens were processed exactly the same way as the FD group. The same pathologist, who was blind to the clinical diagnosis, examined all specimens.

\section{Statistical analysis}

Data from patients with FD and the control group (NERD) were subjected to the D'Augustino and Pearson omnibus normality test. ${ }^{21}$ The results were expressed as means for parametric measurements and medians for nonparametric data. Difference between means was calculated using the Student's $t$-test while difference between medians was determined using the Mann-Whitney U test. Significant difference was set at $P<0.05$.

\section{Results}

One hundred and twenty patients participated in the study (Table 1). There were 68 patients with FD (30 males, $44.1 \%$; and 38 females, $55.9 \%$ ); and 52 patients with NERD (28 males, 53.8\% and 24 females, 46.2\%).

The mean ages of patients with FD and NERD were $48.18 \pm 8.25$ and $46.62 \pm 7.77$ years, respectively. The difference between the means was not statistically significant $(t=1.053, d f=118, P=0.2944)$.

Table I Gender distribution of patients with functional dyspepsia and their counterparts with non-erosive reflux disease

\begin{tabular}{llll}
\hline Group & Male & Female & Total \\
\hline Functional dyspepsia & 30 & 38 & 68 \\
Non-erosive reflux disease & 28 & 24 & 52 \\
Total & 58 & 62 & 120 \\
\hline
\end{tabular}




\section{Histology of duodenal mucosa}

Regarding the histology of duodenal mucosa (Table 2), the total inflammatory scores of patients with FD and NERD were 242 and 66 respectively. The difference between the medians was statistically significant (Mann-Whitney $\mathrm{U}=1,168, P=0.0011$ ). The total scores of chronic inflammatory cells for patients with FD and NERD were 66 and 8 respectively; the difference between the median scores was statistically significant (MannWhitney $\mathrm{U}=1,060, P<0.0001)$. The villus-crypt ratios in FD and NERD were 16 and 8 , respectively; the difference between the medians was not statistically significant (Mann-Whitney $\mathrm{U}=1,684, P=0.6823)$. The hyperplasia scores of Brunner's glands in FD and NERD were 32 and 20 respectively; the difference between the median scores was not statistically significant (Mann-Whitney $U=1,616, P=0.3499$ ). Gastric metaplasia scores in FD and NERD were 10 and 0 , respectively, a difference that was statistically significant (Mann-Whitney $\mathrm{U}=1,508, P=0.0041)$. Neutrophilic activity scores in FD and NERD were 46 and 8 , respectively; the difference between the median scores was statistically significant (Mann-Whitney $\mathrm{U}=1,108, P<0.0001)$. Eosinophilic infiltration scores for FD and NERD were 40 and 16, respectively; the difference between the median scores was not statistically significant (Mann-Whitney $\mathrm{U}=1,452, P=0.0518$ ). H. pylori scores for FD and NERD were 34 and 6, respectively, which was statistically significant (Mann-Whitney $\mathrm{U}=1,088, P<0.0001$ ).

A positive correlation was demonstrated between duration of symptoms and total inflammatory score in FD (Pearson $r=0.7848, P<0.0001$ ). A positive correlation was also demonstrated between duration of symptoms and total inflammatory score in NERD, but this did not reach statistical significance (Pearson $r=0.08417, P=0.5530$ ).

\section{Discussion}

A significant fraction of the average gastroenterology practice is devoted to the management of functional gastrointestinal disorders, of which FD is one of the most frequent. This study amply demonstrates a high degree of inflammation in the duodenal mucosa of patients with FD. This observation is in agreement with emerging trends in the pathogenesis of functional gastrointestinal disorders, including FD and irritable bowel syndrome (IBS).

Gut function may be altered by low numbers of inflammatory cells positioned at strategic locations such as in proximity of enteric nerves. It is beginning to be recognized that an intact epithelium in the absence of mucosal inflammation does not exclude the presence of inflammation in the deeper layers of the gut that can result in altered gut function. ${ }^{22}$ The availability of more sensitive techniques to assess inflammation such as immunohistochemistry or molecular methods may result in a new definition of inflammation in the gut.

There is growing evidence that previous infection and persistent low-grade inflammation play an important role in the pathogenesis of gut functional diseases. A large epidemiological study has identified infectious gastroenteritis as the most significant environmental risk factor for the development of IBS. ${ }^{23}$ IBS symptoms have been reported to develop in a significant proportion of subjects with documented Campylobacter, Salmonella, Escherichia coli, Shigella infections, and viral infections. ${ }^{24-27}$ Increased intraepithelial lymphocytes (IEL) and lamina propria lymphocytes, together with elevated numbers of enteroendocrine cells, were found in patients with postinfectious IBS. ${ }^{28}$

The pathophysiology of post-infectious dyspepsia bears some resemblance to post-infectious IBS. However, results might be different depending on the investigated site and offending agent. Most previous studies on post-infectious functional gastrointestinal diseases have focused on bacterial causes of gastroenteritis, which are characterized by inflammation. ${ }^{24-27}$ However, they may occur also after Giardia lamblia infection ${ }^{28}$ and viral gastroenteritis ${ }^{29}$ where inflammation is mild or absent.

Table 2 Histology of duodenal mucosa in functional dyspepsia and non-erosive reflux disease

\begin{tabular}{|c|c|c|c|c|}
\hline $\begin{array}{l}\text { Histological parameter } \\
\text { (score) }\end{array}$ & $\begin{array}{l}\text { Functional dyspepsia } \\
(n=68)\end{array}$ & $\begin{array}{l}\text { Non-erosive reflux } \\
\text { disease }(n=52)\end{array}$ & $\begin{array}{l}\text { Mann-Whitney } \\
\text { U }\end{array}$ & $P$-value \\
\hline Total inflammatory score & $242(2.500)$ & $66(1.000)$ & $\mathrm{I}, \mathrm{I} 68$ & $0.0011 *$ \\
\hline Chronic inflammatory cells & $66(0.500)$ & $8(0.0)$ & 1,060 & $<0.0001 *$ \\
\hline Villus-crypt ratio & $16(0.0)$ & $8(0.0)$ & 1,684 & 0.6823 \\
\hline $\begin{array}{l}\text { Brunner's gland hyperplasia and } \\
\text { prolapse into lamina propria }\end{array}$ & $32(0.0)$ & $20(0.0)$ & 1,616 & 0.3499 \\
\hline Gastric metaplasia & $10(0.0)$ & $0(0.0)$ & $\mathrm{I}, 508$ & $0.004 I^{*}$ \\
\hline Neutrophilic activity & $46(0.5000)$ & $8(0.0)$ & $\mathrm{I}, 108$ & $<0.000 I^{*}$ \\
\hline Eosinophilic infiltration & $40(0.0)$ & $16(0.0)$ & $\mathrm{I}, 452$ & 0.0518 \\
\hline Helicobacter pylori & $34(0.5000)$ & $6(0.0)$ & $\mathrm{I}, 088$ & $<0.000 I^{*}$ \\
\hline
\end{tabular}

Notes: Figures in parentheses indicate median scores. *Statistically significant. 
It is noteworthy that patients with FD in this study had unspecified onset FD rather than post-infectious FD. However, there are two reasons to posit that a good number of them may have been post-infectious. The first is the fact that the patients come from a tropical environment where gastrointestinal infections are rife. The second reason is the high degree of duodenal inflammation, coupled with varied cellular infiltration. There is a need to conduct prospective studies on patients with gastrointestinal infections to determine the real magnitude of post-infectious FD in Nigeria.

The difference between the score on duodenal chronic inflammatory cells in FD and NERD patients was highly statistically significant $(P<0.0001)$. This observation is similar to results obtained from a similar study that showed that post-infectious FD is associated with persisting focal T-cell aggregates, decreased cluster of differentiation (CD) 4+ cells and increased macrophages in the duodenum. ${ }^{30} \mathrm{Chronic}$ inflammatory cells, however, lack specificity as increased infiltration may be seen in many conditions, including immunological disorders, use of non-steroidal anti-inflammatory drugs (NSAIDs), lymphocytic colitis, collagenous colitis, and bacterial overgrowth. The importance of these conditions in Nigerian patients with FD remains to be shown.

The score on villus-crypt ratio was higher in FD than NERD but the difference did not reach statistical significance ( $P=0.6823$ ). This is not surprising because villous atrophy is a striking feature of gluten sensitive enteropathy (GSE). Features useful in distinguishing peptic duodenitis from GSE include the relative lack of architectural changes in non-specific duodenitis, scant polymorphonuclear leukocyte infiltrate, and the absence or focal presence of gastric metaplasia in GSE. ${ }^{31}$ Severe inflammation, however, may be very difficult to distinguish from GSE and some assessment of IEL together with the clinicopathological correlation is the best way to distinguish between the two different causes of inflammation in the duodenum. ${ }^{31}$ Increased IELs with villous atrophy and crypt hyperplasia is a classic feature of GSE. ${ }^{32}$

H. pylori infection score was higher in FD than NERD and the difference was highly significant $(P<0.0001)$. Half of the patients with FD in this study had histologically demonstrable infection. The prevalence may have been higher if a wash-off period had been allowed for patients who took acid suppressants and antibiotics. The reported prevalence of $H$. pylori infection in patients with FD varies from $39 \%$ to $87 \% .{ }^{33}$ The effect of $H$. pylori eradication on dyspeptic symptoms in FD has been evaluated in several large, well-designed randomized controlled trials, but the results were conflicting. ${ }^{34,35}$ However, a recently published systematic review and meta-analysis from the Chinese literature found that the summary odds ratio for improvement in dyspeptic symptoms in patients with FD after H. pylori eradication was 3.61, suggesting that the role of this infection is much larger in the Chinese population. ${ }^{36}$ This remains to be shown in African populations where H. pylori prevalence is equally very high.

The neutrophilic activity score was significantly higher in FD than NERD patients $(P<0.0001)$. This is an expected morphological alteration in situations where gastrointestinal infection is prevalent. Neutrophilic infiltration is a measure of activity in duodenitis. ${ }^{37,38}$ Mixed acute and chronic inflammatory cell infiltrate in the lamina propria and infiltration of polymorphonuclear neutrophils into the surface epithelium characterize severe duodenitis and this was the pattern in FD patients in this study. Heavy polymorphonuclear invasion is associated with epithelial degeneration, cytoplasmic vacuolization, intercellular edema, and frequent microerosions and true erosions. H. pylori can be identified in the degenerated epithelium. ${ }^{37}$ Other possible etiologies include gluten-sensitive enteropathy, Crohn's disease, autoimmune enteropathy, food allergy, and other gastrointestinal infections. ${ }^{13}$

Gastric metaplasia in the duodenum was significantly more prevalent in FD than NERD. This acquired condition is related to gastric acid secretion and H. pylori infection. ${ }^{39}$ H. pylori may increase gastrin and gastric acid secretion. Gastric acid secretion and, consequently, acid loading of the duodenal bulb are also related to the type and grade of chronic gastritis. ${ }^{39}$ Duodenal gastric metaplasia and $H$. pylori are both usually found in the proximal duodenum. H. pylori colonizes the duodenal mucosa and such colonization leads to a chronic active duodenitis..$^{31,40,41}$ The classification of gastric metaplasia into incomplete, intermediate, and complete depended on the amount of mucin in the metaplastic cells. ${ }^{20}$

The duodenal infiltration score by eosinophils was higher in FD than NERD but the difference was not statistically significant. Eosinophils are key effector cells of the innate immune system within the gastrointestinal tract. Intestinal eosinophils protect vertebrates against parasitic infestations, particularly helminths.

Brunner's gland hyperplasia was more common in FD than NERD. The difference did not reach statistical significance and the significance is difficult to deduce because the pathogenesis of this morphological alteration remains unclear. It has been suggested that $H$. pylori infection may play a role in the pathogenesis of Brunner's gland hamartomas. ${ }^{42}$ A pathogenic link, however, is difficult to draw given the 
rarity of these lesions and the high prevalence of $H$. pylori in the general population. Another theory is that these hamartomas may form as a hyperplastic reaction to inflammation, given the inflammatory cell infiltrate (typically lymphocytes) occasionally witnessed histologically. Supporting evidence for this assertion is insufficient given that the presence of lymphocytes is not unusual in normal submucosa throughout the gastrointestinal tract. ${ }^{43}$

The positive correlation between duration of dyspeptic symptoms and duodenal inflammatory score in FD might be an important observation. Immune activation and persistent low-grade inflammation are thought to be operative in functional gastrointestinal disorders. A significant increased prevalence of FD was reported by Mearin et al up to 1-year after an outbreak of Salmonella gastroenteritis. ${ }^{44}$ In another study by Kindt et al, ${ }^{30}$ focal aggregates of $\mathrm{CD} 8+\mathrm{T}$ cells, decrease in $\mathrm{CD} 4+\mathrm{T}$ cells, and increased macrophage counts surrounding the duodenal crypts persisted for months after the acute infectious episodes, suggesting delayed or impaired termination of the inflammatory response even after adequate removal of the infecting pathogen. In fact, recent epidemiological data indicate that these changes can persist for at least 8 years or more. ${ }^{45}$ These findings call for research into the potential role of some form of anti-inflammatory medication treatment for these conditions.

In conclusion, FD is characterized by a high degree of duodenal inflammation in Nigerian patients. The cellular infiltration cuts across the spectrum of acute, chronic, and specific forms of inflammation. Chronic inflammatory cells and neutrophils are particularly very common. H. pylori infection is demonstrable in the duodenal mucosa of half of our patients with FD. The severity and varied nature of these changes suggests that $H$. pylori infection and possibly other gastrointestinal infections may have a central role in producing the morphological alterations in FD patients. There is an urgent need for more research into the therapeutic implications of these findings.

\section{Disclosure}

The authors report no conflicts of interest in this work.

\section{References}

1. Tack J, Talley NJ, Camilleri M, et al. Functional gastroduodenal disorders. Gastroenterology. 2006;130(5):1466-1479.

2. El-Serag HB, Talley NJ. Systemic review: the prevalence and clinical course of functional dyspepsia. Aliment Pharmacol Ther. 2004; 19(6):643-654.

3. Talley NJ, Silverstein MD, Agréus L, Nyrén O, Sonnenberg A, Holtmann G. AGA technical review: evaluation of dyspepsia. American Gastroenterological Association. Gastroenterology. 1998;114(3): $582-595$.
4. Jeong JJ, Choi MG, Cho YS, et al. Chronic gastrointestinal symptoms and quality of life in the Korean population. World J Gastroenterol. 2008;14(41):6388-6394.

5. Piessevaux H, De Winter B, Louis E, et al. Dyspeptic symptoms in the general population: a factor and cluster analysis of symptom groupings. Neurogastroenterol Motil. 2009;21(4):378-388.

6. Shaib Y, El-Serag HB. The prevalence and risk factors of functional dyspepsia in a multiethnic population in the United States. Am J Gastroenterol. 2004;99(11):2210-2216.

7. Nwokediuko SC, Ijoma U, Obienu O. Functional dyspepsia: subtypes, risk factors, and overlap with irritable bowel syndrome in a population of African patients. Gastroenterol Res Pract. 2012;2012:562393

8. Stanghellini V, Tosetti C, Paternico A, et al. Risk indicators of delayed gastric emptying of solids in patients with functional dyspepsia. Gastroenterology. 1996;110(4):1036-1042.

9. Sarnelli G, Caenepeel P, Geypens B, Janssens J, Tack J. Symptoms associated with impaired gastric emptying of solids and liquids in functional dyspepsia. Am J Gastroenterol. 2003;98(4):783-788.

10. Tack J, Piessevaux H, Coulie B, Caenepeel P, Janssens J. Role of impaired gastric accommodation to a meal in functional dyspepsia. Gastroenterology. 1998;115(6):1346-1352.

11. Tack J, Caenepeel P, Fischler B, Piessevaux H, Janssens J. Symptoms associated with hypersensitivity to gastric distention in functional dyspepsia. Gastroenterology. 2001;121(3):526-535.

12. Haug TT, Svebak S, Wilhelmsen I, Berstad A, Ursin H. Psychological factors and somatic symptoms in functional dyspepsia. A comparison with duodenal ulcer and healthy controls. J Psychosom Res. 1994;38(4): 281-291.

13. Mandeville KL, Krabshuis J, Ladep NG, Mulder CJ, Quigley EM, Khan SA. Gastroenterology in developing countries: issues and advances. World J Gastroenterol. 2009;15(23):2839-2854.

14. Lindkvist P, Enquselassie F, Asrat D, Muhe L, Nilsson I, Giesecke J. Risk factors for infection with Helicobacter pylori - a study of children in rural Ethiopia. Scand J Infect Dis. 1998;30(4):371-376.

15. Dominici P, Bellentani S, Di Biase AR, et al. Familial clustering of Helicobacter pylori infection: population based study. BMJ. 1999;319(7209):537-540.

16. Nabwera HM, Nguyen-Van-Tam JS, Logan RF, Logan RP. Prevalence of Helicobacter pylori infection in Kenyan schoolchildren aged 3-15 years and risk factors for infection. Eur J Gastroenterol Hepatol. 2000;12(5):483-487.

17. Webb PM, Knight T, Greaves S, et al. Relation between infection with Helicobacter pylori and living conditions in childhood: evidence for person to person transmission in early life. $B M J$. 1994;308(6931):750-753.

18. Malaty HM, Paykov V, Bykova O, et al. Helicobacter pylori and socioeconomic factors in Russia. Helicobacter. 1996;1(2):82-87.

19. Serra S, Jani PA. An approach to duodenal biopsies. J Clin Pathol. 2006;59(11):1133-1150.

20. Urakami Y, Sano T. Endoscopic duodenitis, gastric metaplasia and Helicobacter pylori. J Gastroenterol Hepatol. 2001;16(5):513-518.

21. D' Augustino RB, Pearson ES. Testing for departures from normality. Biometrika. 1973;60:613-622.

22. Törnblom H, Lindberg G, Nyberg B, Veress B. Full-thickness of the jejunum reveals inflammation and enteric neuropathy in irritable bowel syndrome. Gastroenterology. 2002;123(6):1972-1979.

23. Rodríguez LA, Ruigómez A. Increased risk of irritable bowel syndrome after bacterial gastroenteritis: cohort study. BMJ. 1999; 318(7183):565-566.

24. Spiller RC, Jenkins D, Thornley JP, et al. Increased rectal mucosal enteroendocrine cells, $\mathrm{T}$ lymphocytes, and increased gut permeability following acute Campylobacter enteritis and in post-dysenteric irritable bowel syndrome. Gut. 2000;47(6):804-811.

25. Gwee KA, Collins SM, Read NW, et al. Increased rectal mucosal expression of interleukin 1 beta in recently acquired post-infectious irritable bowel syndrome. Gut. 2003;52(4):523-526. 
26. Wang LH, Fang XC, Pan GZ. Bacillary dysentery as a causative factor of irritable bowel syndrome and its pathogenesis. Gut. 2004;53(8): 1096-1101.

27. James C, Thabane M, Borgaonkar M, et al. Postinfectious irritable bowel syndrome is transient following a food-borne outbreak of acute gastroenteritis attributed to a viral pathogen. Gastroenterology. 2004; 26(Suppl 2):A53.

28. Dizdar V, Gilja OH, Hausken T. Increased visceral sensitivity in Giardiainduced postinfectious irritable bowel syndrome and functional dyspepsia. Effect of the 5HT3-antagonist ondansetron. Neurogastroenterol Motil. 2007;19(12):977-982.

29. Marshall JK, Thabane M, Borgaonkar MR, James C. Postinfectious irritable bowel syndrome after a food-borne outbreak of acute gastroenteritis attributed to a viral pathogen. Clin Gastroenterol Hepatol. 2007;5(4):457-460.

30. Kindt S, Tertychnyy A, de Hertogh G, Geboes K, Tack J. Intestinal immune activation in presumed post-infectious functional dyspepsia. Neurogastroenterol Motil. 2009;21(8):832-e56.

31. Jeffers MD, Hourihane DO. Coeliac disease with histological features of peptic duodenitis: value of assessment of intraepithelial lymphocytes. $J$ Clin Pathol. 1993;46(5):420-424.

32. Mino-Kenudson M, Brown I, Lauwers GY. Histopathological diagnosis of gluten-sensitive enteropathy. Curr Diagn Pathol. 2005;11:274-283.

33. Lambert JR. The role of Helicobacter pylori in nonulcer dyspepsia. A debate - for. Gastroenterol Clin North Am. 1993;22(1):141-151.

34. Moayyedi P, Soo S, Deeks J, et al. Systematic review and economic evaluation of Helicobacter pylori eradication treatment for non-ulcer dyspepsia. Dyspepsia Review Group. BMJ. 2000;321(7262):659-664.

35. Laine L, Schoenfeld P, Fennerty MB. Therapy for Helicobacter pylori in patients with nonulcer dyspepsia. A meta-analysis of randomized, controlled trials. Ann Intern Med. 2001;134(5):361-369.

36. Jin X, Li YM. Systematic review and meta-analysis from Chinese literature: the association between Helicobacter pylori eradication and improvement of functional dyspepsia. Helicobacter. 2007;12(5): 541-546.
37. Caselli M, Gaudio M, Chiamenti CM, et al. Histologic findings and Helicobacter pylori in duodenal biopsies. J Clin Gastroenterol. 1998;26(1):74-80.

38. Taha AS, Dahil S, Nakashabendi, Lee FD, Sturrock RD, Russell RI. Duodenal histology, ulceration, and Helicobacter pylori in the presence or absence of non-steroidal anti-inflammatory drugs. Gut. 1993;34(9): 1162-1166.

39. Voutilainen M, Juhola M, Färkkilä M, Sipponen P. Gastric metaplasia and chronic inflammation at the duodenal bulb mucosa. Dig Liver Dis. 2003;35(2):94-98.

40. Madsen JE, Vetvik K, Aase S. Helicobacter-associated duodenitis and gastric metaplasia in duodenal ulcer patients. APMIS. 1991;99(11): 997-1000.

41. Wyatt JI, Rathbone BJ, Sobala GM, et al. Gastric epithelium in the duodenum: its association with Helicobacter pylori and inflammation. J Clin Pathol. 1990;43(12):981-986.

42. Kovacević I, Ljubicić N, Cupić H, et al. Helicobacter pylori infection in patients with Brunner's gland adenoma. Acta Med Croatica. 2001;55(4-5):157-160.

43. Rocco A, Borriello P, Compare D, et al. Large Brunner's gland adenoma: case report and literature review. World $J$ Gastroenterol. 2006;12(12):1966-1968.

44. Mearin F, Pérez-Oliveras M, Perelló A, et al. Dyspepsia and irritable bowel syndrome after a Salmonella gastroenteritis outbreak: one-year follow-up cohort study. Gastroenterology. 2005;129(1): 98-104.

45. Marshall JK, Thabane M, Garg AX, Clark WF, Moayyedi P, Collins SM; Walkerton Health Study Investigators. Eight year prognosis of postinfectious irritable bowel syndrome following waterborne bacterial dysentery. Gut. 2010;59(5):605-611.
Clinical and Experimental Gastroenterology

\section{Publish your work in this journal}

Clinical and Experimental Gastroenterology is an international, peerreviewed, open access journal, publishing all aspects of gastroenterology in the clinic and laboratory, including: Pathology, pathophysiology of gastrointestinal disease; Investigation and treatment of gastointestinal disease; Pharmacology of drugs used in the alimentary tract;

\section{Dovepress}

Immunology/genetics/genomics related to gastrointestinal disease. This journal is indexed on CAS. The manuscript management system is completely online and includes a very quick and fair peer-review system. Visit http://www.dovepress.com/testimonials.php to read real quotes from published authors. 